\title{
Re: Larval Therapy from Antiquity to the Present Day: Mechanisms of Action, Clinical Applications and Future Potential
}

\author{
Whitaker IS, Twine C, Whitaker MJ, Welck M, Brown CS, Shandall A \\ Morriston Hospital, Clinic of Burns and Plastic Surgery, Swansea, United Kingdom \\ Postgrad Med J 2007;83:409-13.
}

\section{EDITORIAL COMMENT}

Non-healing chronic wounds present a major health problem despite medical and technological advances in the management of atherosclerotic or diabetic wounds. There are many well described methods such as vacuum pump therapy, hyperbaric oxygen therapy, ozone therapy, and growth factor injection. On the other hand, some ancient therapies have been reevaluated for their efficacy in the treatment of non-healing chronic wounds. One of these alternative and complementary methods is maggot therapy [maggot debridement therapy (MDT), biodebridement, biosurgery or larval therapy]. MDT is the intentional application of live, "medical-grade" and sterile fly larvae (Lucilia sericata) to wounds for debridement, disinfection, and ultimately wound healing. In the United States, medicinal maggots are approved by the Food and Drug Administration as a prescription-only, single-use medical device since 2004. There are many scientific reports on this topic in the medical literature. These larvae make an excellent debridement for necrotic tissues in the wound area in addition to antibacterial effect and production of substances to induce wound healing. There is evidence in the literature on the successful use of larval therapy for traumatic wounds that fail to heal; postsurgical wound infections and perineal gangrene (Fournier's gangrene) have also been treated with maggot therapy after unsuccessful antibiotic and surgical treatments. In our opinion, next generation transgenic larval therapies will be reliable treatment options for chronic non-healing wounds in the near future.

Fehmi Narter, MD, PhD

बCopyright 2018 by the Association of Urological Surgery / Journal of Urological Surgery published by Galenos Publishing House. 